\title{
Prostate specific antigen testing is associated with men's psychological and physical health and their healthcare utilisation in a nationally representative sample: a cross-sectional study
}

\author{
Evelyn M Flahavan ${ }^{1 *+}$, Frances J Drummond ${ }^{2 \dagger}$, Kathleen Bennett ${ }^{1}$, Thomas I Barron ${ }^{1}$ and Linda Sharp ${ }^{2}$
}

\begin{abstract}
Background: Prostate cancer incidence has risen considerably in recent years, primarily due to Prostate Specific Antigen (PSA) testing in primary care. The objective of this study was to investigate associations between PSA testing and the psychological and physical health, and healthcare utilisation of men in a population where PSA testing is widespread.

Methods: A cross-sectional study was carried out in a population-representative sample of men $\geq 50$ years enrolled in The Irish Longitudinal Study on Ageing (TILDA). TILDA participants underwent structured interviews, health assessments and completed standardised questionnaires. Men were classified as ever/never having received a PSA test. Multivariate logistic regression (Odds Ratios (OR) and 95\% Confidence Intervals (Cl) was used to determine associations between PSA testing, and men's psychological and physical health and healthcare utilisation.

Results: This analysis included 3,628 men, 68.2\% of whom ever had a PSA test. In adjusted analysis, men with sub-threshold depression were significantly less likely to have had a PSA test, $(\mathrm{OR}=0.79,95 \% \mathrm{Cl}$ 0.64-0.97). Likelihood of having a PSA test was inversely associated with anxiety, but this was not significant ( $\mathrm{OR}=0.79,95 \% \mathrm{Cl}$ 0.57-1.09). Frailty $(\mathrm{OR}=0.61,95 \% \mathrm{Cl} 0.31-1.05)$ and eligibility for free primary care $(\mathrm{OR}=0.63,95 \% \mathrm{Cl} 0.52-0.77)$ were also inversely associated with PSA testing. Positive associations were observed between PSA testing and more chronic illnesses $(\mathrm{OR}=1.11,95 \% \mathrm{Cl} 1.05-1.19)$, more primary care visits $(\mathrm{OR}=1.03,95 \% \mathrm{Cl} 1.01-1.05)$ and preventative health practices, including cholesterol testing and influenza vaccination $(\mathrm{OR}=1.35,95 \% \mathrm{Cl} 1.13-1.60)$.

Conclusions: Men's psychological and physical health and their healthcare utilisation are associated with PSA testing in primary care. The association between poorer psychological health, in particular sub-threshold depression, and reduced likelihood of PSA testing in primary care requires further investigation. These findings may have wider implications for other cancer screening.
\end{abstract}

\section{Background}

Prostate cancer incidence has increased in the last two decades, due to increasing prostate specific antigen (PSA) testing and subsequent prostate biopsy [1]. Results from two large randomised controlled trials, have not definitively answered the question regarding the benefit of PSA testing on mortality [2,3]. Despite this, the rate

\footnotetext{
* Correspondence: flahavae@tcd.ie

${ }^{\dagger}$ Equal contributors

'Department of Pharmacology \& Therapeutics, Trinity College, University of Dublin, Dublin, Ireland

Full list of author information is available at the end of the article
}

of PSA testing in Ireland is high [4] and the number of PSA tests performed continues to rise [5]. The majority of PSA tests originate in general practice $[4,5]$. This opportunistic testing has led to an increase in prostate cancer incidence, younger age at diagnosis and a shift towards more localized disease [5,6]. Increased prostate cancer detection has important consequences for men's quality-of-life $[7,8]$. There is no consensus between guidelines internationally on the use of PSA testing $[9,10]$ and PSA testing of asymptomatic men is not a national policy in Ireland $[11,12]$. It is therefore important to understand 
factors associated with PSA testing of men in general practice.

Psychological health negatively impacts breast, cervical and colorectal cancer screening [13,14]. Its impact on cancer screening in men [15] and on PSA testing has received little attention, however, and results have been conflicting due to small sample sizes and different measures used [16-18]. In addition, a small number of studies have recently reported that markers of healthcare utilisation influenced whether men have PSA tests and other cancer screening $[17,19,20]$.

Our objective was to investigate, at the population level, associations between PSA testing and men's psychological and physical health and their health services utilisation.

\section{Methods}

\section{Setting}

Ireland has a mixed public-private healthcare system. Approximately one-third of the population are eligible for the state-funded General Medical Services (GMS) Scheme, as determined by means-test and age [21], which entitles them to free General Practitioner (GP) and hospital visits and prescriptions for a small fee per item. GPs are reimbursed for GMS patients by the Health Services Executive. Approximately half the population have private health insurance (PHI). However, most insurance plans do not cover GP visits, and patients pay between $€ 50$ and 60 per visit.

\section{Study population}

This study population consisted of males aged $\geq 50$ years participating in wave 1 (2009-2011) of The Irish Longitudinal Study on Aging (TILDA) [22]. TILDA is a study of the health, lifestyle and financial situation of a populationrepresentative sample of people aged $\geq 50$ years involving Computer Aided Personal Interview (CAPI) in participants' homes, a Self-Completion Questionnaires (SCQ) and comprehensive health assessment (HA) in one of two health centres. Where travel to health centres was unfeasible ( $10 \%$ of participants), nurses performed the HA in participant's homes (Additional file 1). TILDA was approved by the Faculty of Health Sciences Research Ethics Committee of Trinity College Dublin. Potential participants, who were unable to give consent due to dementia or cognitive impairment, were excluded.

\section{Outcome variable}

The main outcome variable was ever having had a PSA test. Men were included if they gave a definitive answer to the CAPI question asking had they ever had "a PSA blood test to screen for prostate cancer". Men who responded "don't know" or declined to answer were excluded $(\mathrm{n}=116)$.

\section{Covariates}

\section{Healthcare utilisation}

The self-reported healthcare utilisation variables recorded were i) number of GP visits in the previous year; eligibility for GMS [23] (yes/no), ii) cholesterol testing (ever/never), iii) influenza vaccination (ever/never), and iv) number of regular medicines (prescription/other) including chronic cardio-preventative medication, statins, and aspirin (yes/no) classified using WHO ATC Classification.

Three scales were used to measure psychological health; depression was assessed using the Centre for Epidemiologic Studies Depression (CES-D) scale (scored as 0-7 not depressed; 8-15 sub-threshold; $\geq 16$ case-level depression [24]); anxiety was assessed using the Hospital Anxiety and Depression Scale (HADS-A): (scored as 0-7 not anxious; 8-10 borderline; $\geq 11$ case-level anxiety [25]); global cognitive function was assessed using the Mini Mental State Examination (MMSE; scored as 26-30 normal cognitive function; 20-25 mild cognitive impairment; $<20$ moderate cognitive impairment [26]). Mild and moderate cognitive impairment groups were combined because of the small number of men in the latter group. Participants for whom data was unavailable were classified as "unspecified" for each of these categories [22].

Men's overall physical health was measured by summing the number of self-reported chronic illnesses from the following list: heart attack, heart failure, angina; stroke; diabetes; hypertension; high cholesterol; lung disease; asthma; cataracts; cancer; Parkinson's disease; peptic ulcer; arthritis; osteoporosis or hip fracture. Men taking medications in the WHO-ATC category G04C were classified as having been treated for Benign Prostatic Hypertrophy (BPH). Previous cancer diagnosis (yes/no) was identified separately. A frailty score was derived within TILDA from five measurements; selfreported weight-loss of $\geq 4.5 \mathrm{~kg}$ in the year pre-interview; weakness based on grip-strength; self-reported exhaustion; gait speed; and low physical activity. Other variables associated with frailty were: self-reported arthritis, joint replacement and osteoporosis (yes/no), hip or wrist fracture (ever/never). Subjective health status variables investigated included overall self-rated health, and self-rated emotional or mental health (excellent/very good, good, fair/poor).

Socio-demographic characteristics including age, marital status, work status, smoking status, highest educational level achieved and PHI status, were recorded at the CAPI.

\section{Statistical analysis}

Univariate analyses (chi-square test, Wilcoxson rank-sum) were used to identify associations between covariates and ever having had a PSA test. Logistic regression was used to build a multivariate model of predictors of PSA testing. Analysis was conducted in two stages. Firstly, a core 
model was developed from socio-demographic, healthcare utilisation and health status variables previously associated with PSA testing (age, marital status, education, employment, smoking status, number of GP visits) and covariates with a p-value $<0.1$ in univariate analyses. Collinearity was addressed by including one of two potentially correlated variables (e.g. number of chronic illnesses, but not number of medicines). Covariates retained in the core model were: number of chronic illnesses, influenza vaccine, prior cancer diagnosis, treated for BPH, and GMS eligibility. In stage two, psychological and physical health measures were added separately to the core model, to assess their independent association with PSA testing.

Sensitivity analysis was performed to examine effects on multivariate risk estimates of PSA testing of excluding men who had a previous prostate cancer diagnosis $(\mathrm{n}=93)$. Individual comorbidities were assessed for association with PSA testing in the core model, as an additional analysis.

TILDA data V 1-7-3 and STATA V 12 were used for analyses. Significance at $\mathrm{p}<0.05$ was assumed.

\section{Results}

\section{Study population characteristics}

The median age of men was 63 years (IQR $56-71, \mathrm{~N}=$ 3,628). 68.2\% reported ever having a PSA test (Table 1). Of these men, $84.2 \%$ returned the SCQ, and HA data was available for $72.3 \%$ (Figure 1).

\section{Stage 1: Core model}

The core multivariate model is presented in Table 2. Ever having a cholesterol test was the factor most strongly associated with PSA testing in univariate analysis $(\mathrm{OR}=17.0$ 95\% CI 12.9-22.4). Therefore, to assess other independent associations with PSA testing, this variable was removed from the model. In multivariate analyses, physical health (more chronic conditions (OR $=1.11$ per unit increase in conditions, 95\% CI 1.05-1.19); previous cancer diagnosis $(\mathrm{OR}=2.74,95 \% \mathrm{CI} 1.74-4.30)$; $\mathrm{BPH}$ treatment $(\mathrm{OR}=2.66$, 95\%CI 1.65-4.27)), healthcare utilisation (increased number of GP visits (OR $=1.01,95 \%$ CI 1.01-1.05; having an influenza vaccination $(\mathrm{OR}=1.35,95 \% \mathrm{CI} 1.13-1.60)$ ); and sociodemographic variables (higher educational attainment and being married/cohabiting compared to other marital status) were associated with increased likelihood of having PSA tests. Men were significantly less likely to have had PSA tests if they were: current smokers $(\mathrm{OR}=0.56,95 \% \mathrm{CI}$ $0.45-0.69)$, GMS eligible ( $\mathrm{OR}=0.63,95 \% \mathrm{CI} 0.52-0.77)$ or were not employed (OR $=0.67,95 \%$ CI $0.53-0.85)$ (Table 2$)$.

\section{Stage 2: associations between psychological and physical} health and PSA testing

One-fifth of these men had depression, of whom 15\% and $7 \%$ had sub-threshold and case-level depression, respectively. Prevalence of borderline and case-level anxiety were $16.3 \%$ and $5.4 \%$, respectively. Men with subthreshold depression were significantly less likely to have had a PSA test(s) (adjusted OR $=0.79,95 \%$ CI 0.62-0.97). Men with case-level anxiety had reduced likelihood of PSA testing in unadjusted analyses compared to nonanxious men, but this was not significant following adjustment $(\mathrm{OR}=0.79,95 \% \mathrm{CI}$ 0.57-1.09). Lower self-rated emotional or mental health was associated with reduced likelihood of PSA testing in univariate analysis, but this was no longer significant in adjusted analyses (Table 3).

Patients with a degree of cognitive impairment were significantly less likely to have had PSA tests. Those with mild-moderate cognitive impairment were less likely to have had PSA tests, compared to those with unimpaired cognition, though non-significantly $(\mathrm{OR}=0.79,95 \% \mathrm{CI}$ 0.58-1.08).

Frailty was associated with reduced likelihood of PSA testing, this was significant for men who were pre-frail (adjusted $\mathrm{OR}=0.68,95 \% \mathrm{CI} 0.56-0.83$ ). Individual frailty measures associated with non-testing were low grip strength $(\mathrm{OR}=0.84,95 \% \mathrm{CI}$ 0.69-1.02), low gait speed $(\mathrm{OR}=0.61,95 \% \mathrm{CI} 0.43-0.86)$ and low levels of physical activity (OR 0.66, 95\%CI 0.50-0.87) (Additional file 2). Men who reported heart attack/heart failure/angina $(\mathrm{OR}=0.62$, $95 \% \mathrm{CI} 0.47-0.80)$, stroke (OR $=0.55,95 \% \mathrm{CI} 0.32-0.95)$ and lung disease $(\mathrm{OR}=0.64,95 \% \mathrm{CI} 0.43-0.95)$ were significantly less likely to have had PSA tests in adjusted analyses (Additional file 3).

Exclusion of men who had a prostate cancer diagnosis $(\mathrm{N}=93)$ did not affect associations between any covariates in the core model and ever having a PSA test, except previous cancer diagnosis (Additional file 4).

\section{Discussion}

PSA testing is widespread in Ireland. However, our findings suggest that men with lower self-reported physical and psychological health, including depression, anxiety, cognitive impairment and frailty were less likely to have had a PSA test, while men with very good self-reported health were more likely to have had a PSA test, in this nationally representative sample of men aged 50 years or older, after adjusting for socio-demographic factors. Increased healthcare utilisation was also associated with increased likelihood of PSA testing, however men who were eligible for free healthcare were less likely to have been tested.

These results should be interpreted with some care, as the study was cross-sectional in design; however we considered three hypotheses of health behaviour to explain these observations $[27,28]$. Firstly, there is evidence of a 'healthy user effect' [27] whereby men taking preventative medication e.g. statins and receiving influenza vaccinations were more likely to have had PSA tests. The 
Table 1 Characteristics of the study population, stratified according to whether they ever or never had a PSA test (N (\%), unless otherwise stated)

\begin{tabular}{|c|c|c|c|c|c|}
\hline \multicolumn{3}{|c|}{ Population characteristics } & \multicolumn{2}{|c|}{ PSA tested } & \multirow[b]{3}{*}{ p-value } \\
\hline & & & \multirow{2}{*}{$\begin{array}{r}\text { Ever } \\
68.2 \%)\end{array}$} & \multirow{2}{*}{$\begin{array}{r}\text { Never } \\
\mathrm{N}=1,153(31.8 \%)\end{array}$} & \\
\hline & & & & & \\
\hline \multicolumn{6}{|c|}{ Socio-demographic characteristics } \\
\hline Age at interview & Years & Median, (IQR) & $64(57,71)$ & $59(54,69)$ & $<0.001$ \\
\hline \multirow[t]{4}{*}{ Marital status } & Married & N (\%) & $1,916(77.4)$ & $795(69.0)$ & $<0.001$ \\
\hline & Single & N (\%) & $248(10.0)$ & $178(15.4)$ & \\
\hline & Sep/Divorced & N (\%) & $112(4.5)$ & $89(7.7)$ & \\
\hline & Widowed & N (\%) & $199(8.0)$ & $91(7.9)$ & \\
\hline \multirow[t]{3}{*}{ Education } & Primary & N (\%) & $771(31.2)$ & $425(36.9)$ & $<0.001$ \\
\hline & Secondary & N (\%) & $952(38.5)$ & $463(40.2)$ & \\
\hline & Third Level & N (\%) & $752(30.4)$ & $265(23.0)$ & \\
\hline \multirow[t]{3}{*}{ Employment } & Employed & N (\%) & $1,007(40.7)$ & $508(44.1)$ & $<0.001$ \\
\hline & Retired & N (\%) & $1,225(49.5)$ & $406(35.2)$ & \\
\hline & Other & N (\%) & $243(9.8)$ & $239(20.7)$ & \\
\hline \multirow[t]{3}{*}{ Smoking status } & Never & N (\%) & 919 (37.2) & $374(32.4)$ & $<0.001$ \\
\hline & Past & N (\%) & $1,215(49.1)$ & $471(40.8)$ & \\
\hline & Current & N (\%) & $340(13.7)$ & $308(26.7)$ & \\
\hline $\mathrm{PHI}$ & At time of CAPI & N (\%) & $1,618(65.4)$ & $514(44.6)$ & $<0.001$ \\
\hline \multicolumn{6}{|l|}{ Health-care utilisation } \\
\hline No. of GP visits & year pre-CAPI & Median (IQR) & $3(1,5)$ & $2(0,4)$ & $<0.001$ \\
\hline Cholesterol test & Ever & N (\%) & 2,408 (97.4) & $791(68.9)$ & $<0.001$ \\
\hline Influenza Vaccine & Ever & N (\%) & $1,352(54.6)$ & $468(40.6)$ & $<0.001$ \\
\hline \multirow[t]{4}{*}{ No. of medicines } & Self-reported & Median (IQR) & $2(0,4)$ & $1(0,3)$ & $<0.001$ \\
\hline & BPH-Medicine & N (\%) & $166(4.7)$ & $21(1.8)$ & $<0.002$ \\
\hline & Aspirin & N (\%) & $673(27.2)$ & $216(18.7)$ & $<0.001$ \\
\hline & Statin & N (\%) & $869(35.1)$ & $277(24.0)$ & $<0.001$ \\
\hline GMS eligibility & At time of CAPI & N (\%) & $1,072(43.3)$ & $544(47.2)$ & 0.029 \\
\hline \multicolumn{6}{|c|}{ Physical, mental and emotional health } \\
\hline \multirow[t]{3}{*}{ Overall health ${ }^{1}$} & Excellent/Very good & N (\%) & $1,398(56.5)$ & $601(52.3)$ & 0.012 \\
\hline & Good & N (\%) & $690(27.9)$ & $376(32.7)$ & \\
\hline & Fair/Poor & N (\%) & $386(15.6)$ & $173(15.0)$ & \\
\hline No. chronic illnesses & & Median (IQR) & $2(1,3)$ & $1(0,2)$ & $<0.001$ \\
\hline \multirow[t]{2}{*}{ Cancer diagnosis } & Ever & N (\%) & $179(7.2)$ & $24(2.1)$ & $<0.001$ \\
\hline & Prostate cancer & N (\%) & $93(3.8)$ & $0(0)$ & $<0.001$ \\
\hline \multirow[t]{4}{*}{ Frailty } & Not frail & N (\%) & $1,265(51.1)$ & $486(42.2)$ & $<0.001$ \\
\hline & Pre-frail & N (\%) & $481(19.5)$ & $244(21.2)$ & \\
\hline & Frail & N (\%) & $57(2.3)$ & $23(2.0)$ & \\
\hline & Unrecorded & $N(\%)$ & $670(27.1)$ & $400(34.7)$ & \\
\hline \multirow[t]{3}{*}{ Emotional/Mental health ${ }^{1}$} & Excellent/Very good & N (\%) & $1,604(64.8)$ & $689(59.8)$ & 0.007 \\
\hline & Good & N (\%) & $676(27.3)$ & 347 (30.1) & \\
\hline & Fair/Poor & N (\%) & $195(7.9)$ & $117(10.2)$ & \\
\hline Depression score & CESD & Median (IQR) & $3(0,6)$ & $3(1,8)$ & 0.001 \\
\hline
\end{tabular}


Table 1 Characteristics of the study population, stratified according to whether they ever or never had a PSA test (N (\%), unless otherwise stated) (Continued)

\begin{tabular}{|c|c|c|c|c|c|}
\hline \multirow[t]{3}{*}{ Depression } & No & N (\%) & $1,954(79.9)$ & $847(74.6)$ & 0.002 \\
\hline & Sub-threshold & N (\%) & $344(14.1)$ & $200(17.6)$ & \\
\hline & Case-Level & N (\%) & $151(6.2)$ & $88(7.8)$ & \\
\hline Anxiety score & HADS-A (SCQ) & Median (IQR) & $4(2,7)$ & $5(2,7)$ & 0.167 \\
\hline \multirow[t]{4}{*}{ Anxiety categorical } & Not anxious & N (\%) & $1,679(67.8)$ & $695(60.2)$ & 0.001 \\
\hline & Borderline & N (\%) & $277(11.2)$ & $115(10.0)$ & \\
\hline & Case-Level & N (\%) & $118(4.8)$ & $75(6.5)$ & \\
\hline & Unclassified & N (\%) & $401(16.2)$ & $268(23.2)$ & \\
\hline Cognition & MMSE score & Median (IQR) & $29(27,30)$ & $29(28,30)$ & \\
\hline \multirow[t]{3}{*}{ MMSE categorical } & Normal & N (\%) & $1,677(67.8)$ & $699(60.6)$ & $<0.001$ \\
\hline & Mild /moderate Impairment & N (\%) & $157(6.3)$ & $83(7.2)$ & \\
\hline & Unrecorded & N (\%) & $641(25.9)$ & $371(32.2)$ & \\
\hline
\end{tabular}

${ }^{1}$ Self-rated overall and emotional or mental health relative to others of the same age; PHI: Private Health Insurance; CAPI: Computer Aided Personal Interview; SCQ: self-completed questionnaire, IQR: Interquartile range.

healthy user effect is a multidimensional concept incorporating 'health-seeking' tendencies, i.e. healthier patients request or accept more screening tests and have increased adherence to medications, but it also incorporates 'health status' i.e. the ability of patients, physically and cognitively to attend primary care and to get prescriptions filled [27]. Multi-morbidity results in polypharmacy and increased health services utilisation [29]. We found that, despite adjusting for number of GP visits, men with more chronic illnesses were more likely to have been tested, suggesting that some PSA tests can be ascribed to the 'surveillance hypothesis' i.e. men with coexisting conditions have more frequent contact with the healthcare system facilitating early diagnosis $[20,28]$. However, while not the central focus of this paper, we found that the association between comorbidity and PSA testing depended on the coexisting disease, which was in agreement with other studies [30]. In this cohort, likelihood of PSA testing was increased in men with angina, high cholesterol, cataracts and hypertension ('surveillance hypothesis'), but was negatively associated with frailty, cardiac diseases and stroke, suggesting that poorer physical health may distract a GP from undertaking, or offering men a PSA test, the 'competing demand hypothesis' [28].

The negative associations observed, in this cohort, between poorer psychological health and likelihood of PSA testing are further evidence of the 'competing demand hypothesis.' The impact of poor psychological health on the likelihood of men having a PSA test has received little attention. Men with sub-threshold depression were significantly less likely to have PSA tests than men who were not depressed, suggesting that somatic symptoms associated with depression may be more pertinent during healthcare visits, or that GPs may be less likely to initiate discussions about PSA testing and prostate cancer with depressed men for fear of exacerbating their condition [31]. Our findings concur with previous work which observed lower rates of breast, cervical and colorectal cancer screening among people with depression $[13,14,32]$, despite increased usage of primary care services [14]. However, we found that case-level depression was not associated with PSA testing. This may be due to various reasons; men with case-level depression may be receiving management for depression and thus may be more likely to be PSA tested, consistent with the 'surveillance hypothesis'; the number of men with case-level depression may be too small to detect significant effects; or the effect of case-level depression on PSA testing may be no longer significant when other aspects of psychological health e.g. anxiety was included in the model. In support of the latter hypothesis, Kotwal et al. observed that men with depressive symptoms were less likely to have PSA tests however, this effect was mediated by levels of perceived stress [19] which concurs with the surveillance hypothesis. While stress was not measured in this cohort, we found that case-level anxiety was associated with reduced likelihood of PSA testing in univariate, but not adjusted analysis.

Anxiety has been shown to influence PSA testing in a number of ways. A review found variations in anxiety levels across the prostate cancer continuum from screening to beyond treatment [16]. Dale et al., observed that PSA screening was associated with increased levels of anxiety in men, highest in those with high pre-dispositional anxiety, but this mostly subsided upon receipt of a normal result [16]. Furthermore, anxiety about having prostate cancer predicted both PSA testing and avoidance of screening, the latter especially among asymptomatic men with a family history of prostate cancer. To further 


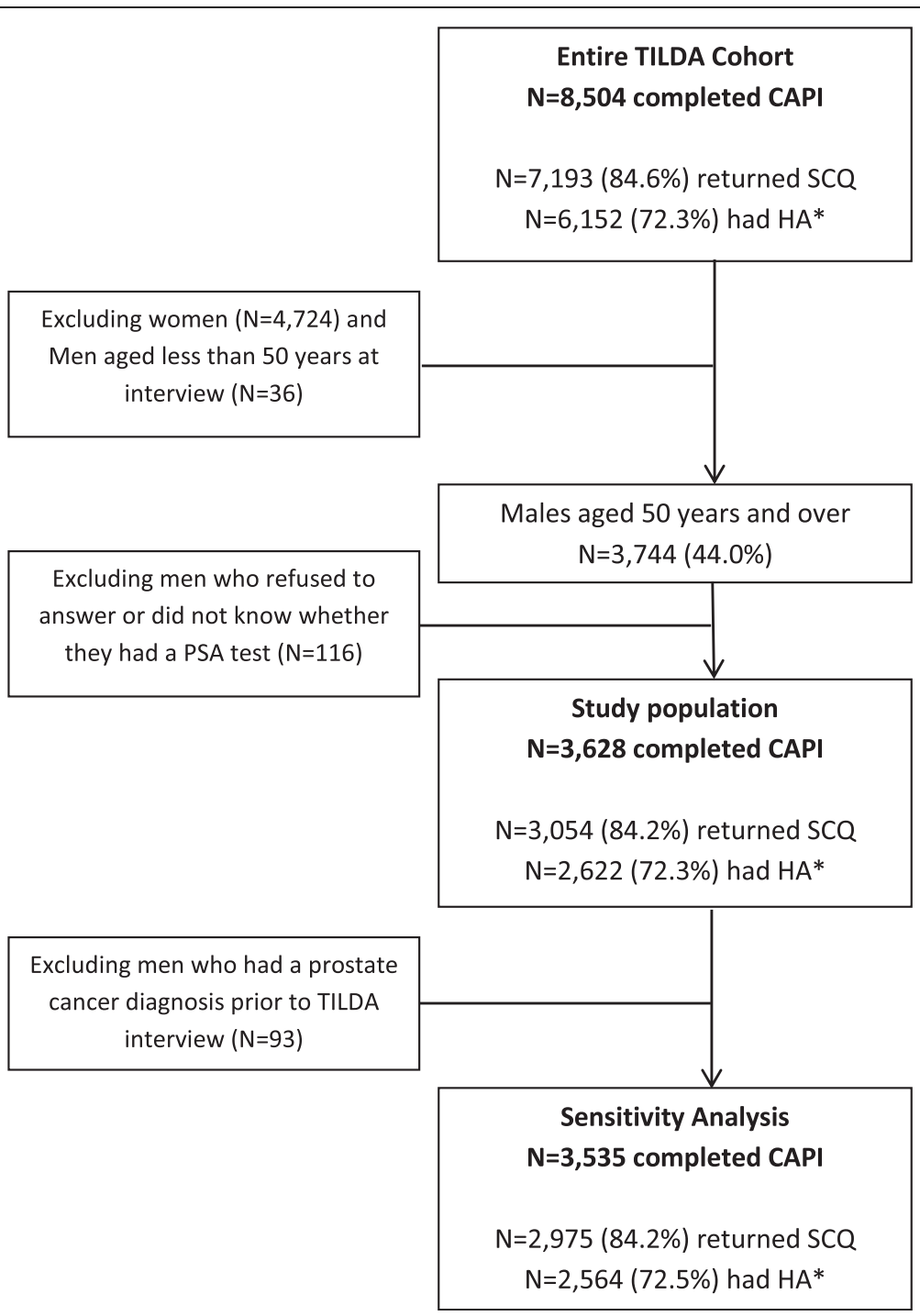

Figure 1 Flow diagram of the study population identified from the TILDA study.

elucidate the effect of anxiety on PSA testing Consedine et al., in a small study of 533 American men, aged 45 to 70 years, investigated the effect of three components of anxiety i.e. dispositional anxiety, prostate cancer worry, and screening fear on frequency of PSA testing (and digital rectal exams (DRE)) [18]. They concluded that cancer worry propelled men to have PSA tests, screening fear deterred men from having DRE, but not PSA tests, and trait anxiety was associated with more frequent DREs, but not with PSA testing [18]. Furthermore, a recent study observed that the association between anxiety and PSA testing is dependent on the number of GP visits [19]; men were less likely to be PSA tested if they had higher anxiety and attended their GP once, but men with higher anxiety who attended their GP more frequently were more likely to be tested. However, it is difficult to draw comparisons between studies due to different study designs, populations examined and instruments used to measure psychological health (depression, anxiety and stress) [13-16,18,19].

Men with increased cognitive impairment were also significantly less likely to have had PSA tests, which again may be explained by the 'competing demands' hypothesis. This is the first time associations between psychological health and PSA testing has been observed in men in Ireland and our findings add to the growing body of literature on the effect of psychological health on preventative health and cancer screening.

Eligibility for free healthcare (GMS eligibility) is associated with more frequent GP visits [23], however, despite adjustment for socio-demographic, health, and healthcare factors including number of GP visits, GMS eligibility was negatively associated with PSA testing, which 
Table 2 Univariate (OR $95 \% \mathrm{Cl})$ and multivariate (OR $95 \% \mathrm{Cl})$ analysis of associations between socio-demographic characteristics, healthcare utilisation, and physical health, and ever having had a PSA test (Stage 1: Core Model)

\begin{tabular}{|c|c|c|c|c|c|c|c|}
\hline \multicolumn{2}{|c|}{ Variables associated with PSA testing } & \multicolumn{3}{|c|}{ Univariate analysis } & \multicolumn{3}{|c|}{ Multivariate analysis } \\
\hline & & OR & $95 \% \mathrm{Cl}$ & p-value & OR & $95 \% \mathrm{Cl}$ & p-value \\
\hline \multicolumn{8}{|c|}{ Socio-demographic factors } \\
\hline Age at interview & Years & 1.03 & $1.02-1.04$ & $<0.001$ & 1.02 & $1.00-1.03$ & 0.012 \\
\hline \multirow[t]{4}{*}{ Marital status } & Married & 1.00 & Ref & & 1.00 & Ref & \\
\hline & Single & 0.58 & $0.47-0.72$ & $<0.001$ & 0.69 & $0.55-0.87$ & 0.001 \\
\hline & Separated/Divorced & 0.52 & $0.39-0.70$ & $<0.001$ & 0.68 & $0.50-0.92$ & 0.014 \\
\hline & Widowed & 0.91 & $0.70-1.18$ & 0.466 & 0.70 & $0.53-0.94$ & 0.017 \\
\hline \multirow[t]{3}{*}{ Education } & Primary & 1.00 & Ref & & 1.00 & Ref & \\
\hline & Secondary & 1.13 & $0.96-1.33$ & 0.131 & 1.31 & $1.09-1.57$ & 0.004 \\
\hline & Third Level & 1.56 & $1.30-1.88$ & $<0.001$ & 1.49 & $1.22-1.83$ & $<0.001$ \\
\hline \multirow[t]{3}{*}{ Employment } & Employed & 1.00 & Ref & & 1.00 & Ref & \\
\hline & Retired & 1.52 & $1.30-1.78$ & $<0.001$ & 1.23 & $0.99-1.53$ & 0.056 \\
\hline & Other & 0.51 & $0.42-0.63$ & $<0.001$ & 0.67 & $0.53-0.85$ & 0.001 \\
\hline \multirow[t]{3}{*}{ Smoking status } & Never & 1.00 & Ref & & 1.00 & Ref & \\
\hline & Past & 1.05 & $0.89-1.23$ & 0.553 & 0.96 & $0.81-1.14$ & 0.634 \\
\hline & Current & 0.45 & $0.37-0.55$ & $<0.001$ & 0.56 & $0.45-0.69$ & $<0.001$ \\
\hline Private health insurance & Yes & 2.35 & $2.04-2.71$ & $<0.001$ & & & \\
\hline \multicolumn{8}{|c|}{ Healthcare utilisation factors } \\
\hline Number of GP visits & Continuous & 1.04 & $1.02-1.06$ & $<0.001$ & 1.03 & $1.01-1.05$ & 0.001 \\
\hline Influenza vaccine & Ever & 1.76 & $1.53-2.03$ & $<0.001$ & 1.35 & $1.13-1.60$ & 0.001 \\
\hline GMS scheme eligible & Yes & 0.86 & $0.74-0.98$ & 0.029 & 0.63 & $0.52-0.77$ & $<0.001$ \\
\hline Number of medicines & Continuous & 1.12 & $1.08-1.15$ & $<0.001$ & & & \\
\hline Cholesterol test & Yes & 17.00 & $12.9-22.4$ & $<0.001$ & & & \\
\hline \multicolumn{8}{|l|}{ Physical health } \\
\hline Chronic illnesses & Continuous & 1.25 & $1.19-1.32$ & $<0.001$ & 1.11 & $1.05-1.19$ & 0.001 \\
\hline Prior cancer diagnosis & Yes & 3.66 & $2.38-5.64$ & $<0.001$ & 2.74 & $1.74-4.30$ & $<0.001$ \\
\hline Treated BPH & Yes & 3.87 & $2.45-6.14$ & $<0.001$ & 2.66 & $1.65-4.27$ & $<0.001$ \\
\hline
\end{tabular}

Variables for which multivariate ORs are presented are those contained within the core model; Multivariate ORs are adjusted for age (continuous), marital status (married/single/separated or divorced/widowed), highest education level attained (primary/secondary/third level), employment status (employed/retired/other), smoking status (never/past/current), number of GP visits in the past year (continuous), receipt of influenza vaccine (ever/never), number of chronic illness reported (continuous), GMS eligibility (yes/no), prior cancer diagnosis (yes/no) and reported receipt of medicines for BPH.

is consistent with income-related inequality in uptake of PSA testing observed in Ireland and elsewhere [33]. This highlights the issue that in mixed public-private systems, free healthcare services does not produce equity in uptake of primary care services, and may in part explain the higher prostate cancer incidence in higher socioeconomic groups [34].

Socio-demographic factors were strong predictors of PSA testing and our findings are broadly in agreement with others $[19,20,33]$. Married men were more likely to have PSA tests possibly because their wives engage in breast and cervical cancer screening (Drummond et al. unpublished data). Odds of PSA testing were greatly reduced in current smokers, this trend concurs with findings from previous studies [35]. Smoking-related illnesses may be prioritised by GPs, the 'competing demands hypothesis' and/or smokers may avoid engagement with health services because they anticipate unwanted advice to quit smoking [36].

This study has several strengths. It is a large sample, representative of the population [22], with data on a wide range of variables. Standardised measures of depression, anxiety and cognitive function were used, although stress was not measured. We acknowledge several limitations; data on PSA testing was self-reported, which is subject to recall bias [37]. However, that more than two-thirds of men reported ever having a PSA test is not surprising given the level of PSA testing in Ireland has risen since the mid 1990's [38]; by 2004, 41.2\% of men aged 50 years and older had had a PSA test [6], and the number of PSA 
Table 3 Univariate (OR $95 \% \mathrm{Cl}$ ) and multivariate (OR $95 \% \mathrm{Cl}$ ) analysis of associations between psychological and physical health covariates, and ever having had a PSA test (Stage 2)

\begin{tabular}{|c|c|c|c|c|c|c|c|}
\hline \multirow[t]{2}{*}{ Physical, mental and emotional health } & & \multicolumn{3}{|c|}{ Univariate analysis } & \multicolumn{3}{|c|}{ Multivariate analysis } \\
\hline & & OR & $95 \% \mathrm{Cl}$ & p-value & OR & $95 \% \mathrm{Cl}$ & p-value \\
\hline \multirow[t]{3}{*}{ Self-rated health } & Excellent/Very good & 1.00 & Ref & & 1.00 & Ref & \\
\hline & Good & 0.79 & $0.67-0.92$ & 0.003 & 0.78 & $0.66-0.93$ & 0.005 \\
\hline & Fair/Poor & 0.96 & $0.78-1.18$ & 0.688 & 0.88 & $0.69-1.38$ & 0.320 \\
\hline \multirow[t]{3}{*}{ Self-rated emotional/mental health } & Excellent/Very good & 1.00 & Ref & & 1.00 & Ref & \\
\hline & Good & 0.84 & $0.72-0.98$ & 0.026 & 0.91 & $0.77-1.08$ & 0.258 \\
\hline & Fair/Poor & 0.72 & $0.56-0.92$ & 0.008 & 0.82 & $0.62-1.08$ & 0.158 \\
\hline Depression & CES-D & 0.98 & $0.97-0.99$ & 0.002 & 0.99 & $0.98-1.00$ & 0.126 \\
\hline \multirow[t]{3}{*}{ Depression } & No & 1.00 & Ref & & 1.00 & Ref & \\
\hline & Sub-threshold & 0.75 & $0.62-0.90$ & 0.003 & 0.79 & $0.64-0.97$ & 0.025 \\
\hline & Case-level & 0.74 & $0.56-0.98$ & 0.035 & 0.85 & $0.62-1.15$ & 0.293 \\
\hline Anxiety & Continuous & 0.98 & $0.96-1.00$ & 0.078 & 1.00 & $0.97-1.02$ & 0.791 \\
\hline \multirow[t]{4}{*}{ Anxiety categorical } & Not anxious & 1.00 & Ref & & Ref & 1.00 & \\
\hline & Borderline & 0.99 & $0.79-1.26$ & 0.980 & 1.02 & $0.79-1.30$ & 0.906 \\
\hline & Case-level & 0.65 & $0.48-0.88$ & 0.003 & 0.79 & $0.57-1.09$ & 0.159 \\
\hline & Unclassified & 0.62 & $0.52-0.74$ & $<0.001$ & 0.71 & $0.59-0.87$ & 0.001 \\
\hline Cognition: MMSE score & Continuous & 1.04 & $1.01-1.08$ & 0.023 & 1.05 & $1.01-1.10$ & 0.024 \\
\hline \multirow[t]{3}{*}{ MMSE score for cognitive impairment } & Unimpaired & 1.00 & Ref & & 1.00 & Ref & \\
\hline & Mild-moderate & 0.79 & $0.60-1.04$ & 0.096 & 0.79 & $0.58-1.08$ & 0.134 \\
\hline & Unrecorded & 0.72 & $0.62-0.84$ & $<0.001$ & 0.84 & $0.71-1.00$ & 0.049 \\
\hline \multirow[t]{4}{*}{ Frailty } & Not frail & 1.00 & Ref & & 1.00 & Ref & \\
\hline & Pre-frail & 0.76 & $0.62-0.91$ & 0.003 & 0.68 & $0.56-0.83$ & $<0.001$ \\
\hline & Frail & 0.95 & $0.58-1.56$ & 0.846 & 0.61 & $0.35-1.05$ & 0.072 \\
\hline & Unrecorded & 0.65 & $0.55-0.76$ & $<0.001$ & 0.72 & $0.60-0.85$ & $<0.001$ \\
\hline Arthritis & & 1.59 & $1.32-1.91$ & $<0.001$ & 1.23 & $0.99-1.52$ & 0.058 \\
\hline Aspirin & & 1.62 & $1.36-1.92$ & $<0.001$ & 1.18 & $0.96-1.44$ & 0.113 \\
\hline Statin & & 1.71 & $1.46-2.00$ & $<0.001$ & 1.28 & $1.06-1.54$ & 0.009 \\
\hline
\end{tabular}

tests continues to increase [5]. Sensitive information may have been withheld e.g. use of anti-depressants; or chronic conditions misclassified and the strength of some associations with PSA testing may have been limited due to small numbers in sub-groups. A small number of men in this study $(n=93 ; 2.6 \%)$ had a previous prostate cancer diagnosis, and the prevalence of psychological distress (including depression and anxiety) has been shown to be elevated in men with prostate cancer in some studies [39,40], but not others [41]. Analyses were adjusted for previous cancer diagnosis and a sensitivity analysis was conducted excluding men with a previous prostate cancer diagnosis (Additional file 4: Table S4). Finally, there is potentially residual or unmeasured confounding in the analysis for example the influence of GPs, or 'provider effect', on whether men were PSA tested.

\section{Conclusions}

In conclusion, this cross-sectional study provides insight into the characteristics of men who have, and have not had PSA tests in primary care. Men in poorer psychological and physical health, smokers and those eligible for free GP services were less likely to have had PSA tests while men in good overall health and those engaging in health-seeking behaviours were more likely to have been tested. These findings might be considered by physicians and policy makers in the development of public health strategies to improve the appropriateness and equality of prostate cancer detection. 


\section{Additional files}

Additional file 1: Table S1. List of covariates captured by the TILDA study; variables ( $N(\%))$ from the TILDA study included in this study population, for univariate and multivariate analyses.

Additional file 2: Table S2. Univariate (OR 95\% Cl) and multivariate (OR 95\% Cl) analysis of associations between covariates which make up the frailty score, and ever having had a PSA test.

Additional file 3: Table S3. Post-hoc analysis; Univariate (OR 95\% Cl) and multivariate (OR 95\% Cl) analysis of associations between chronic illnesses and ever having had a PSA test.

Additional file 4: Table S4. Assessment of the association between PSA testing (yes/no) and covariates associated with PSA testing having excluded men with prior prostate cancer.

\section{Abbreviations}

PSA: Prostate specific antigen; TILDA: The Irish longitudinal study on ageing; CAPI: Computer assisted personal interview; SCQ: Self completed questionnaire; HA: Health assessment; GMS: General medical services; OR: Odds ratio; Cl: Confidence interval; GP: General practice; WHO ATC: World Health Organisation anatomical therapeutic chemical classification; BPH: Benign prostatic hypertrophy; CES-D: Centre for epidemiologic studies depression; HADS-A: Hospital anxiety and depression scale; PHI: Private health insurance; DRE: Digital rectal examination.

\section{Competing interests}

Since the completion of this study EMF has been employed by Eli Lilly and Company. LS has previously received an unrestricted project grant from Sanofi-Aventis.

\section{Authors' contributions}

EMF participated in the study design, carried out the statistical analysis and drafted the manuscript. FJD participated in the study design and drafted the manuscript. KB, TIB and LS conceived of the study, participated in its design and commented critically on the draft manuscript. All authors contributed to interpretation of the results, and read and approved the final manuscript.

\section{Authors' information}

EMF: Irish Cancer Society Research Scholar in the Department of Pharmacology and Therapeutics TCD (2010-2013) - focusing on Prostate Cancer Pharmacoepidemiology; FJD, PhD is a research fellow/project coordinator at the National Cancer Registry; KB, PhD is an associate professor in Pharmacoepidemiology and statistician in the Department of Pharmacology and Therapeutics TCD; ITB, PhD, is a research fellow in the Department of Pharmacology and Therapeutics TCD; LS PhD, is an epidemiologist at the National Cancer Registry and adjunct professor, Department of Epidemiology and Public Health, UCC.

\section{Acknowledgements}

We would like to acknowledge the cooperation of Rose-Anne Kenny and The Medications working group at the Irish Longitudinal Study on Ageing (TILDA). EMF is supported by a PhD studentship from the Irish Cancer Society (CRS10FLA). TIB and FJD are supported by the Health Research Board Ireland (HRA-2009-221 (TIB), ICE-2011-9 (TIB) HRA_HSR/2010/17 (FJD)). The Irish Cancer Society and the Health Research Board Ireland had no role in the study design; collection, analysis, and interpretation of data; writing of the report; or the decision to submit for publication.

\section{Author details}

${ }^{1}$ Department of Pharmacology \& Therapeutics, Trinity College, University of Dublin, Dublin, Ireland. ${ }^{2}$ National Cancer Registry Ireland, Building 6800, Airport Business Park, Cork, Ireland.

Received: 28 March 2014 Accepted: 4 June 2014

Published: 17 June 2014

\section{References}

1. Ferlay J, Shin HR, Bray F, Forman D, Mathers C, Parkin DM: Estimates of worldwide burden of cancer in 2008: GLOBOCAN 2008. Int J Cancer 2010, 127:2893-2917.
2. Schröder FH, Hugosson J, Roobol MJ, Tammela TL, Ciatto S, Nelen V, Kwiatkowski M, Lujan M, Lilja H, Zappa M, Denis LJ, Recker F, Berenguer A, Määttänen L, Bangma CH, Aus G, Villers A, Rebillard X, van der Kwast T, Blijenberg BG, Moss SM, de Koning HJ, Auvinen A, ERSPC Investigators: Screening and prostate-cancer mortality in a randomized European study. N Engl J Med 2009, 360:1320-1328.

3. Andriole GL, Crawford ED, Grubb RL 3rd, Buys SS, Chia D, Church TR, Fouad MN, Gelmann EP, Kvale PA, Reding DJ, Weissfeld JL, Yokochi LA, O'Brien B, Clapp JD, Rathmell JM, Riley TL, Hayes RB, Kramer BS, Izmirlian G, Miller AB, Pinsky PF, Prorok PC, Gohagan JK, Berg CD, PLCO Project Team: Mortality results from a randomized prostate-cancer screening trial. N Engl J Med 2009, 360:1310-1319.

4. Drummond FJ, Sharp L, Comber H: Major inter-laboratory variations in PSA testing practices: results from national surveys in Ireland in 2006 and 2007. Ir J Med Sci 2008, 177:317-323.

5. Drummond FJ, Barrett E, Burns R, O'Neill C, Sharp L: The number of tPSA tests continues to rise and variation in testing practices persists: a survey of laboratory services in Ireland 2008-2010. Ir J Med Sci 2013. Epub ahead of print.

6. Carsin AE, Drummond FJ, Black A, van Leeuwen PJ, Sharp L, Murray $L$, Connolly D, Egevad L, Boniol M, Autier P, Comber H: Impact of PSA testing and prostatic biopsy on cancer incidence and mortality: comparative study between the Republic of Ireland and Northern Ireland. Cancer Causes Control 2010, 9:1523-31.

7. Gomella LG, Johannes J, Trabulsi EJ: Current prostate cancer treatments: effect on quality of life. Urology 2009, 73(5 Suppl):S28-35.

8. Drummond FJ, Kinnear K, O'Leary E, O'Brien K, Gavin A, Sharp L: Actual and expected treatment-related side-effects predict low health related quality-of-life in prostate cancer survivors PiCTure study. Support Care Cancer 2013, 21(Suppl 1):S1-S301.

9. Wolf AM, Wender RC, Etzioni RB, Thompson IM, D'Amico AV, Volk RJ, Brooks DD, Dash C, Guessous I, Andrews K, DeSantis C, Smith RA, American Cancer Society Prostate Cancer Advisory Committee: American Cancer Society guideline for the early detection of prostate cancer: update 2010. CA Cancer J Clin 2010, 60:70-98.

10. US Preventative Services Task Force: Screening for prostate cancer. Current Recommendation. 2012. http://www.uspreventiveservicestaskforce. org/prostatecancerscreening.htm.

11. National Cancer Control Programme, Health Services Executive: National prostate cancer GP referral guidelines. 2011. http://www.healthlink.ie/ Oncology/NCCP\%20Prostate\%20Cancer\%20Referral\%20Guideline\%20Version \%201.3\%20January\%202011.pdf.

12. Irish College of General Practitioners: Prostate Screening. Quality in practice committee. 2008. http://www.icgp.ie/library_catalogue/index.cfm/ disposition/inline/id/42978/event/catalogue.item.download.html.

13. Consedine NS, Magai C, Krivoshekova YS, Ryzewicz L, Neugut Al: Fear, anxiety, worry, and breast cancer screening behavior: a critical review. Cancer Epidemiol Biomarkers Prev 2004, 13:501-10.

14. Vigod SN, Kurdyak PA, Stewart DE, Gnam WH, Goering PN: Depressive symptoms as a determinant of breast and cervical cancer screening in women: a population-based study in Ontario, Canada. Arch Womens Ment Health 2011, 14:159-68.

15. Kodl MM, Powell AA, Noorbaloochi S, Grill JP, Bangerter AK, Partin MR: Mental health, frequency of healthcare visits, and colorectal cancer screening. Med Care 2010, 48:934-9.

16. Dale W, Bilir $P$, Han M, Meltzer D: The role of anxiety in prostate carcinoma: a structured review of the literature. Cancer 2005, 104:467-78.

17. Eisen SA, Waterman B, Skinner CS, Scherrer JF, Romeis JC, Bucholz K, Heath A, Goldberg J, Lyons MJ, Tsuang MT, True WR: Sociodemographic and health status characteristics with prostate cancer screening in a national cohort of middle-aged male veterans. Urology 1999, 53:516-22.

18. Consedine NS, Adjei BA, Ramirez PM, McKiernan JM: An object lesson: source determines the relations that trait anxiety, prostate cancer worry, and screening fear hold with prostate screening frequency. Cancer Epidemiol Biomarkers Prev 2008, 17:1631-9.

19. Kotwal AA, Schumm P, Mohile SG, Dale W: The influence of stress, depression, and anxiety on PSA screening rates in a nationally representative sample. Medical care 2012, 50:1037-44.

20. Ross LE, Taylor YJ, Howard DL: Trends in prostate-specific antigen test use, 2000-2005. Public health Rep 2011, 126:228-239.

21. Health Services Executive: Medical Card Information. Dublin: Health Services Executive; 2012 
22. The Irish Longitudinal Study on Ageing (TILDA): The Design of the Irish Longitudinal Study on Ageing. 2010. http://www.tcd.ie/tilda/assets/pdf/ DesignReport2010.pdf.

23. Nolan A, Nolan B: Eligibility for free GP care, "need" and GP visiting in Ireland. Eur J Health Econ 2008, 9:157-63.

24. Radloff LS: The CES-D Scale: a self-report depression scale for research in the general population. Appl Psychol Meas 1977, 1:385-401.

25. Zigmond AS, Snaith RP: The hospital anxiety and depression scale. Acta psychiatrica Scandinavica 1983, 67:361-70.

26. Folstein MF, Folstein SE, McHugh PR: "Mini-mental state". A practical method for grading the cognitive state of patients for the clinician. J Psychiatr Res 1975, 12:189-98.

27. Brookhart MA, Patrick AR, Dormuth C, Avorn J, Shrank W, Cadarette SM, Solomon DH: Adherence to lipid-lowering therapy and the use of preventive health services: an investigation of the healthy user effect. Am J Epidemiol 2007, 166:348-54.

28. Fleming ST, McDavid K, Pearce K, Pavlov D: Comorbidities and the risk of late-stage prostate cancer. ScientificWorldJournal 2006, 6:2460-70.

29. Smith SM, Ferede A, O'Dowd T: Multimorbidity in younger deprived patients: an exploratory study of research and service implications in general practice. BMC family practice 2008, 9:6.

30. Fowke JH, Signorello LB, Underwood W 3rd, Ukoli FA, Blot WJ: Obesity and prostate cancer screening among African-American and Caucasian men. Prostate 2006, 66:1371-80.

31. Torta RG, Munari J: Psychological aspects of PSA testing. Nat Rev Urol 2009, 6:513-5.

32. Kodl MM, Powell AA, Noorbaloochi S, Grill JP, Bangerter AK, Partin MR: Mental health, frequency of healthcare visits, and colorectal cancer screening. Med Care 2010, 48:934-9.

33. Burns R, Walsh B, Sharp L, O'Neill C: Prostate cancer screening practices in the Republic of Ireland: the determinants of uptake. J Health Serv Res Pol 2012, 17:206-11.

34. National Cancer Registry Ireland: All Ireland Cancer Atlas 1995-2007. 2011. http://www.ncri.ie/publications/cancer-atlases-and-geographic-studies/ all-ireland-cancer-atlas-1995-2007.

35. Rolison JJ, Hanoch Y, Miron-Shatz T: Smokers: at risk for prostate cancer but unlikely to screen. Addictive behaviors 2012, 37:736-8.

36. Butler CC, Pill R, Stott NC: Qualitative study of patients' perceptions of doctors' advice to quit smoking: implications for opportunistic health promotion. BMJ 1998, 316:1878-81.

37. Rauscher GH, Johnson TP, Cho Yl, Walk JA: Accuracy of self-reported cancer-screening histories: a meta-analysis. Cancer Epidemiol Biomarkers Prev 2008, 17:748-57.

38. Drummond FJ, Carsin AE, Sharp L, Comber H: Trends in prostate specific antigen testing in Ireland: lessons from a country without guidelines. Ir J Med Sci 2010, 179:43-9.

39. Sharpley CF, Bitsika V, Christie DH: Psychological Distress among Prostate Cancer Patients: Fact Or Fiction? Clin Med Oncol 2008, 2:563-72.

40. Watts S, Leydon G, Birch B, Prescott P, Lai L, Eardley S, Lewith G: Depression and anxiety in prostate cancer: a systematic review and meta-analysis of prevalence rates. BMJ Open 2014, 4(3):e003901.

41. Block S, Love A, Macvean M, Duchesne G, Cooper J, Kissane D: Psychological adjustment of men with prostate cancer: A review of the literature. Biopsychosocial Med 2007, 10:1-2.

doi:10.1186/1471-2296-15-121

Cite this article as: Flahavan et al:: Prostate specific antigen testing is associated with men's psychological and physical health and their healthcare utilisation in a nationally representative sample: a cross-sectional study. BMC Family Practice 2014 15:121.

\section{Submit your next manuscript to BioMed Central and take full advantage of:}

- Convenient online submission

- Thorough peer review

- No space constraints or color figure charges

- Immediate publication on acceptance

- Inclusion in PubMed, CAS, Scopus and Google Scholar

- Research which is freely available for redistribution

Submit your manuscript at www.biomedcentral.com/submit
C) Biomed Central 